\title{
Identifikasi Perkebunan Kopi Menggunakan ArcGIS di Kecamatan Pinogu Kabupaten Bone Bolango
}

\author{
Yunita Humola ${ }^{1)}$, Iqrima Staddal ${ }^{3)}$, Romi Djafar ${ }^{3)}$ \\ 1,2,3) Program Studi Mesin dan Peralatan Pertanian, Politeknik Gorontalo, Jl. Muchlis Rahim, Desa Panggulo \\ Barat, Kec. Botupingge, Kab. Bone Bolango, Gorontalo, Indonesia \\ e-mail: yunita.humola@gmail.com
}

\begin{abstract}
ABSTRAK
Salah satu metode penyampaian informasi data spasial yang digunakan untuk memaparkan informasi-informasi yang berhubungan dengan data spasial dan data pendukung lainnya adalah Teknologi SIG (sistem informasi geografis). Teknologi ini mengintegritaskan operasi pengolahan data berbasis database yang biasa digunakan saat ini. Tujuan penelitian ini adalah mengidentifikasi perkebunan kopi di Kecamatan Pinogu. Pinogu adalah nama wilayah kecamatan yang terletak pada bagian paling timur dari Kabupaten Bone Bolango, Provinsi Gorontalo. Kawasan ini terletak di pegunungan tilongkabila di pedalaman hutan kawasan taman nasional bogani nani wartabone pada ketinggian $247 \mathrm{~s} / \mathrm{d} 1600$ mdpl. Kopi pinogu adalah kopi organik yang menjadi produk unggulan di Kabupaten Bone Bolango. Teknik identifikasi perkebunan kopi dilakukan menggunakan teknologi SIG melalui software ArcGIS dengan sumber data berupa data primer dan data sekuder. Data primer pada penelitian ini adalah data sebaran perkebunan kopi yang diambil secara langsung. Sedangkan data sekunder terdiri dari peta administrasi, peta kemiringan lereng, peta penggunaan lahan, peta tanah, peta status kawasan, dan tabulasi komoditas tanaman kopi pinogu di Kecamatan Pinogu. Berdasarkan hasil penelitian diketahui bahwa perkebunan kopi di Kecamatan Pinogu tersebar di Desa Dataran Hijau, Bangio, Pinogu Permai, Pinogu, dan Tilongibila. Beberapa perkebunan kopi didominasi dengan tanah dystropept sebesar $82 \%$, tanah tropaquept $9,4 \%$ dan tropudults 8,6\% dan berada dikelas curam antara 25-40\% dan bahkan ada yang dikelas sangat curam $<40 \%$.
\end{abstract}

Kata Kunci: data spasial, perkebunan kopi, kopi pinogu, ArcGIS

\begin{abstract}
One method of delivering spatial data information that is used to present information related to spatial data and other supporting data is GIS technology (geographical information system). This technology integrates database-based data processing operations that are commonly used today. The purpose of this study was to identify coffee plantations in Pinogu District. Pinogu is the name of a sub-district located in the easternmost part of Bone Bolango Regency, Gorontalo Province. This area is located in the Tilongkabila Mountains in the interior of the Bogani Nani Wartabone National Park area at an altitude of 247 to 1600 meters above sea level. Pinogu coffee is an organic coffee that is the flagship product in Bone Bolango Regency. The identification technique of coffee plantations is carried out using GIS technology through ArcGIS software with data sources in the form of primary data and secondary data. The primary data in this study is the distribution of coffee plantations taken directly. While secondary data consists of administrative maps, slope maps, land use maps, land maps, area status maps, and tabulation of pinogu coffee commodities in Pinogu District. Based on the results of the study, it is known that coffee plantations in Pinogu District are spread in Dataran Hijau, Bangio, Pinogu Permai, Pinogu, and Tilongibila villages. Some coffee plantations are dominated by dystropept soils by $82 \%$, tropaquept soils $9.4 \%$ and tropudults $8.6 \%$ and are in steep grades between $25-40 \%$ and some are even very steep grades $<40 \%$.
\end{abstract}

Keywords: spatial data, coffee plantation, pinogu coffee, ArcGIS 


\section{PENDAHULUAN}

Sektor pertanian memiliki peran penting dalam perekonomian dan keberlangsungan hidup masyarakat, terutama kontribusinya terhadap lapangan kerja dan pangan dalam negeri. Salah satu sektor pertanian adalah tanaman kopi. Tanaman kopi merupakan bagian yang tak terpisahkan dari masyarakat Kabupaten Bone Bolango dan memiliki peran dalam pembangunan daerah, khususnya masyarakat Kecamatan Pinogu. Kopi pinogu dipercaya sebagai peninggalan VOC (Vereenigde Oostindische Compagnie), perusahaan dagang Belanda yang pernah menjajah Indonesia sebelum diambil alih pemerintah Hindia Belanda (https://regional.kompas.com/). Beratus tahun kopi ini tumbuh di perkebunan yang kemudian menjadi hutan, sebagian dibudidayakan masyarakat disekitar desa.

Kecamatan Pinogu, memiliki luasan $40.596 \mathrm{Ha}$ yang dihuni 2.040 jiwa dan memiliki lima desa yaitu Desa Pinogu Induk, Desa Bangiyo, Desa Dataran Hijau, Desa Tilongibilia dan Desa Pinogu Permai. Secara Administrasi Kecamatan Pinogu masuk kedalam Taman Nasional Bogani Nani Wartabone (BPS, 2016). Kecamatan Pinogu terletak di Kabupaten Bone Bolango sekitar $60 \mathrm{KM}$ dari ibukota. Akses menuju Pinogu sampai saat ini begitu sulit untuk dilalui, sehingga membuat sulitnya masyarakat Kecamatan Pinogu menjual hasil panen mereka dalam bentuk biji kopi. Biji kopi diolah langsung secara tradisional oleh masyarakat dan dipasarkan dalam bentuk kopi bubuk.

Salah satu metode penyampaian informasi data spasial yang digunakan untuk memaparkan informasi-informasi yang berhubungan dengan data spasial dan data pendukung lainnya adalah Teknologi GIS (Geographic information System) atau dalam Bahasa Indonesia disingkat SIG (Sistem Informasi Geografis) mengintegritaskan operasi pengolahan data berbasis database yang biasa digunakan saat ini (Hamidi, 2011; Suryani, dkk., 2011).

Telah ada beberapa penelitian tentang Sistem Informasi Geografis pada suatu lahan seperti, "Pembuatan Peta Potensi Lahan Berdasarkan Kondisi Fisik Lahan Menggunakan Metode Weighted Overlay" (Adininggar, 2016) dan "Sistem Informasi Geografis Pemetaan Lahan Pertanian dan Komoditi Hasil Panen Kabupaten Kudus" (Susanto, 2016). Namun, penelitian untuk mengidentifikasi perkebunan kopi di Kecamatan Pinogu belum dilakukan. Oleh karena itu, berdasarkan uraian di atas sehingga penelitian ini dilakukan untuk megidentifikasi dan mengklasifikasikan sebaran perkebunan kopi di Kecamatan Pinogu.

\section{METODE PENELITIAN}

\section{Jenis dan Tempat Penelitian}

Penelitian ini merupakan penelitian analisis data kuatitatif untuk mengetahui sebaran perkebunan kopi di Kecamatan Pinogu. Analisis dilakukan dengan menggunakan aplikasi ArcGIS.

\section{Sumber dan Pengambilan Data}

Data yang dijadikan sumber penelitian berupa data primer dan data sekunder. Data primer yang diambil pada penelitian ini berupa data sebaran perkebunan kopi di Kecamatan Pinogu. Sedangkan, data sekunder meliputi data-data berikut:

1. Peta administrasi berupa peta luas Kecamatan Pinogu

2. Peta Kemiringan Lereng Kecamatan Pinogu

3. Peta penggunaan lahan Kecamatan Pinogu

4. DEM Kecamatan Pinogu

5. Peta tanah Kecamatan Pinogu

6. Peta status kawasan Kecamatan Pinogu

7. Tabulasi komoditas tanaman kopi di Kecamatan Pinogu

\section{Analisis Data}

Analisis data dilakukan melalui beberapa langkah berikut:

1. Menentukan permasalahan:

- Sebaran perkebunan kopi

- Identifikasi perkebunan kopi yang masuk kawasan hutan lindung (x) dan tidak (y)

2. Mengumpulkan dan menyiapkan data

3. Menentukan metode dan analisis

4. Analisis data spasial menggunakan aplikasi ArcGIS yang terdiri atas:
- Extract
- Overlay
- Proximity
- Statistic

\section{Pembuatan Peta}

Dari data primer dan data sekunder yang telah diolah dan dianalisis maka akan didapatkan data (x) dan data (y). Data ini akan diolah kembali 
menggunakan ArcGis dengan teknik digitasi pada peta.

\section{HASIL DAN PEMBAHASAN}

\section{Sebaran Tanaman kopi di Kecamatan Pinogu}

Secara Geografis Kecamatan Pinogu terletak di Kabupaten Bone Bolango, Provinsi Gorontalo dengan titik koordinat $0^{\circ} 33^{\prime} 0^{\prime \prime}$ LU dan $123^{\circ} 12^{\prime} 0^{\prime \prime}$. Secara administratif berbatasan dengan Kabupaten Bolaang Mongondow Utara, Provinsi Sulawesi Utara dibagian utara dan timur. Bagian Selatan berbatasan dengan Kecamatan Bone dan Kecamatan Bone Raya serta bagian barat berbatasan dengan Kecamatan Suwawa Timur.

Kecamatan Pinogu memiliki luas 40.596 Ha dan terdiri dari 5 Desa yaitu Desa Pinogu, Desa Bangio, Desa Pinogu Permai, Desa Dataran Hijau dan Desa Tilongibila. Desa terluas adalah Desa Bangio yang memiliki luas $12.040 \mathrm{Ha}$, kemudian Desa Dataran Hijau dengan luas 9.220 Ha.Desa Pinogu Permai 8.268 Ha, Desa Pinogu 6.524 Ha dan Desa Tilongibila dengan luas 4.544 Ha (BP3K Kecamatan Pinogu dalam BPS BonBol 2014-2018).

Desa Tilongibila memiliki presentase sebaran perkebunan kopiterbanyak pada pada tahun 2014, 2015 dan 2017. Desa Pinogu Permai pada tahun 2013 dan Desa Pinogu pada tahun 2016 (Gambar 1). Akan tetapi, seperti yang terlihat dari data bahwasanya perubahan luasan tiap tahunnya terlalu tajam. Hal ini membuat data tidak bisa dianalisa karena perubahan yang tidak sistematis.

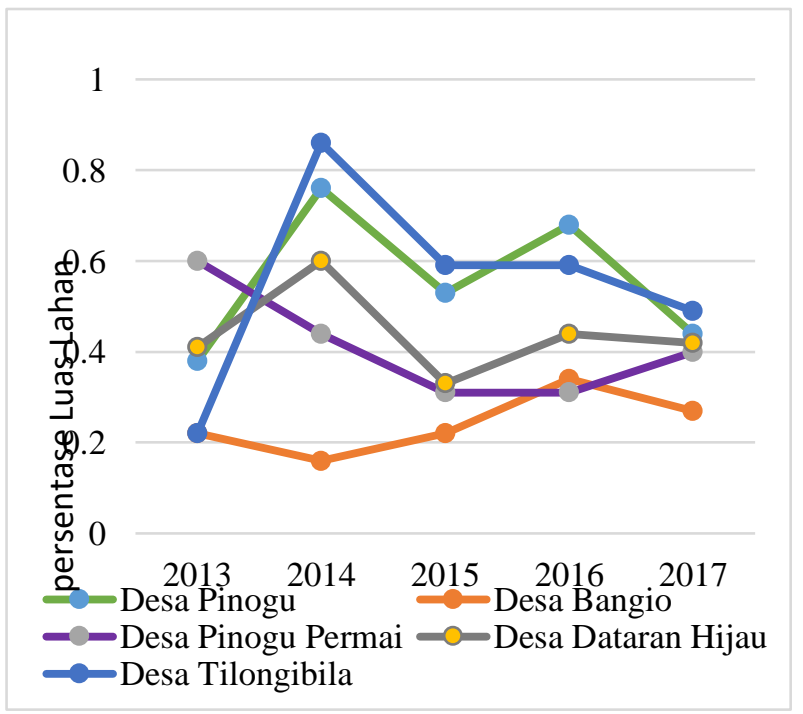

Gambar 1. Grafik Sebaran Tanaman Kopi di Kec. Pinogu

Terdapat dua jenis sebaran kopi pinogu, yaitu point hitam dan putih (Gambar 2). Titik-titik point putih merupakan data yang dikumpulkan dengan menggunakan sistim pointing GPS (Global Positioning System) yaitu menggunakan alat bernama GPS dan menandai tempat tanaman kopinya langsung di lapangan. Sedangkan point hitam adalah data yang dikumpulkan berdasarkan hasil wawancara kepada masyarakat dan aparat Kecamatan Pinogu. Metode ini dilakukan karena medan yang ditempuh sangat sulit dan jauh.

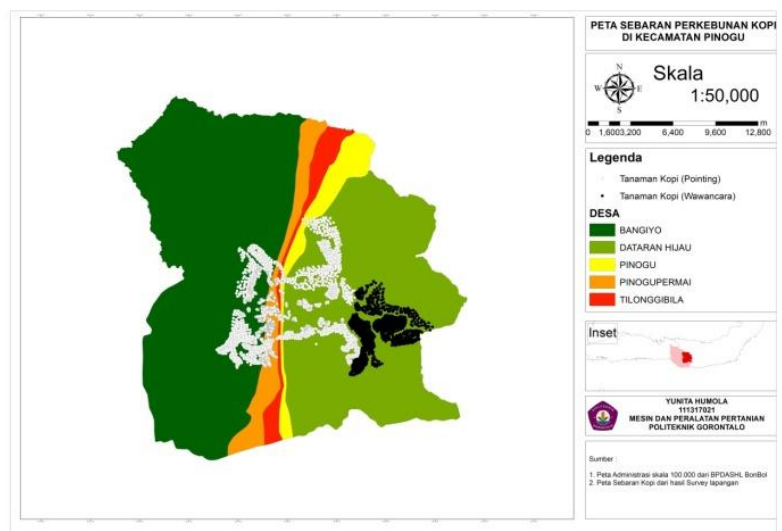

Gambar 2. Peta Sebaran Tanaman Kopi di Kec. Pinogu Berdasarkan Wilayah Administrasi

Secara detail sebaran kopi di Kec. Pinogu disajikan pada Tabel 1.

Tabel 1. Data Sebaran kopi di Kecamatan Pinogu

\begin{tabular}{|l|c|c|}
\hline \multirow{2}{*}{\multicolumn{1}{c|}{ Desa }} & \multicolumn{2}{c|}{ Sebaran Kopi } \\
\cline { 2 - 3 } & $\begin{array}{c}\text { Hasil } \\
\text { Pointing }\end{array}$ & $\begin{array}{c}\text { Hasil } \\
\text { Wawancara }\end{array}$ \\
\hline Bangio & 1.744 Titik & - \\
\hline Dataran Hijau & 1.288 Titik & 930 Titik \\
\hline Pinogu & 99 Titik & - \\
\hline Pinogu Permai & 860 Titik & - \\
\hline Tilongibila & 51 Titik & - \\
\hline Total & 4.042 Titik & 930 Titik \\
\hline
\end{tabular}

Sebaran kopi di Desa Bangio merupakan yang terbanyak dengan hasil pointing 1.744 titik, kemudian Desa Dataran Hijau dengan 1.288 titik, Desa Pinogu Permai dengan 860 titik, disusul Desa Pinogu 99 titik dan Desa Tilongibila dengan 51 titik. Untuk hasil wawancara hanya terdapat pada Desa Dataran Hijau dengan hasil 930 titik. Kecamatan Pinogu menghasilkan kopi 36,34 Ton pada tahun 2017, menjadikannya sebagai penghasil kopi terbesar di Kabupaten Bone Bolango yang disusul oleh Kecamatan Suwawa Timur, kemudian Kecamatan Bolango Utara, Kecamatan Suwawa Selatan dan Kecamatan Kabila Bone. 
Seperti yang terlihat dari peta sebaran perkebunan pada Gambar 2, Desa Dataran Hijau merupakan desa yang memiliki perkebunan kopi terbesar, disusul oleh Desa Bangio, Desa Pinogu Permai, Desa Pinogu dan Desa Tilongibila dengan sebaran tersedikit.

\section{Sebaran Perkebunan Kopi Berdasarkan Kemiringan Lereng}

Tingkat kemiringan pada lereng bisa dilihat dari kontur tanahnya. Kontur merupakan garis tanah yang menghubungkan dari satu titik ke titik yang lainnya. Ada juga yang mengartikan kontur tanah sebagai tinggi rendahnya suatu tanah atau yang disebut topografi. Untuk menentukan kontur maka dilakukan topografi dengan melihat garis kontur yaitu garis horizontal dan garis tinggi sehingga nantinya akan terlihat naik turunnya suatu permukaan tanah. Garis kontur ini dapat memberikan informasi seputar kemiringan tanah rata-rata (slope), perhitungan galian dan timbunan tanah asli.

Kecamatan Pinogu memiliki wilayah dengan topografi berombak sampai bergelombang dengan elevasi antara 237-1.600 Mdpl. Peta kemiringan lereng berdasarkan kelas dibagi menjadi lima kelas yaitu datar (0-8)\%, landau (8-15)\%, agak curam (15$25) \%$, curam (25-45), dan sangat curam $(>45 \%)$.

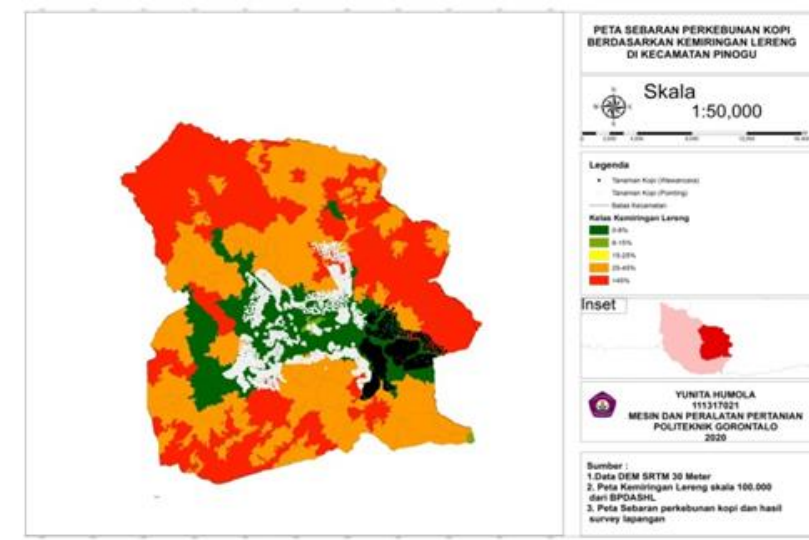

Gambar 3. Peta Sebaran Perkebunan Kopi di Kec.

Pinogu berdasarkan Kemiringan Lereng

Secara detail, sebaran perkebunan kopi di Kec. Pinogu berdasarkan kemiringan lereng dapat dilihat pada Tabel 2. Terdapat perkebunan kopi yang berada di kelas curam antara $25-40 \%$ dan bahkan ada yang dikelas sangat curam $<40 \%$. Terlihat bahwa erosi pada kemiringan tersebut sangat tinggi sesuai dengan pendapat Arsyad (2010) yang menyatakan bahwa semakin curam suatu kemiringan lereng maka erosi akan semakin tinggi. Berdasarkan hal tersebut pengelolaan perkebunan kopi harus dikelola dengan baik melalui konservasi tanah dan air.

Tabel 2. Data Sebaran Kopi berdasarkan Kelas Tanah

\begin{tabular}{|c|c|c|}
\hline \multirow{2}{*}{ Kelas Tanah } & \multicolumn{2}{|c|}{ Tanaman Kopi } \\
\cline { 2 - 3 } & Hasil Pointing & $\begin{array}{c}\text { Hasil } \\
\text { Wawancara }\end{array}$ \\
\hline $0-8 \%$ & 3.124 Titik & 766 Titik \\
\hline $8-15 \%$ & 71 Titik & 9 Titik \\
\hline $15-25 \%$ & 13 Titik & 1 Titik \\
\hline $25-45 \%$ & 442 Titik & 116 Titik \\
\hline$<45 \%$ & 392 Titik & 38 Titik \\
\hline Total & 4.042 Titik & 930 Titik \\
\hline
\end{tabular}

\section{Sebaran Perkebunan Kopi Berdasarkan Jenis Tanah}

Di kecamatan Pinogu terdapat tiga jenis tanah yaitu:

1. Tanah Dystropept atau latosol coklat kemerahan adalah great grup dari ordo tanah inceptisol dengan subordo tropepts. Merupakan tanah yang mempunyai kejenuhan basa $<50 \%$, kedalaman 101-105 cm, tekstur lempung berpasir, reaksi anah masam dengan $\mathrm{pH}$ 5-5,5.

2. Tanah Tropaquept adalah great grup dari ordo tanah inceptisol dengan subordo aquept yang memiliki regim suhu tanah isomesik atau lebih panas. Aquept memiliki drainase alamiah jelek atau sangat jelek dan kalau tanah tidak mengalami drainase buatan, groundwater berada dekat permukaan selama periode tertentu selama setahun, tetapi tidak sepanjang musim. Banyak tanah ini berkembang pada vegetasi hutan, tetapi juga ditemukan pada beragam vegetasi. Aquepts digunakan untuk lahan pertanian, pasture, hutan dan cagar alam.

3. Tanah Tropodultsatau podsolik merah adalah great grup dari tanah ultisol. Merupakan tanah mineral yang tidak berkapur (mengandung kalsium karbonat) dimanapun didalam tanah, memiliki saturasi basa kurang dari $35 \%$ diseluruh tanah. Dikenal juga dengan sebutan tanah liat.

Wilayah Kecamatan Pinogu didominasi dengan tanah Dystropeptsebesar $82 \%$, kemudian tanah tropaquept 9,4\% dan tropudults 8,6\% (Gambar 4). Namun, wilayah yang padat ditanami adalah wilayah berjenis tanah tropodults. Ketiga jenis tanah yang ada di Kecamatan Pinogu termasuk bagus untuk tanaman kopi, apalagi masyarakat pinogu belum menggunakan pupuk kimia untuk tanaman 
kopi mereka. Bisa dikatakan kopi pinogu tergolong kopi organik.

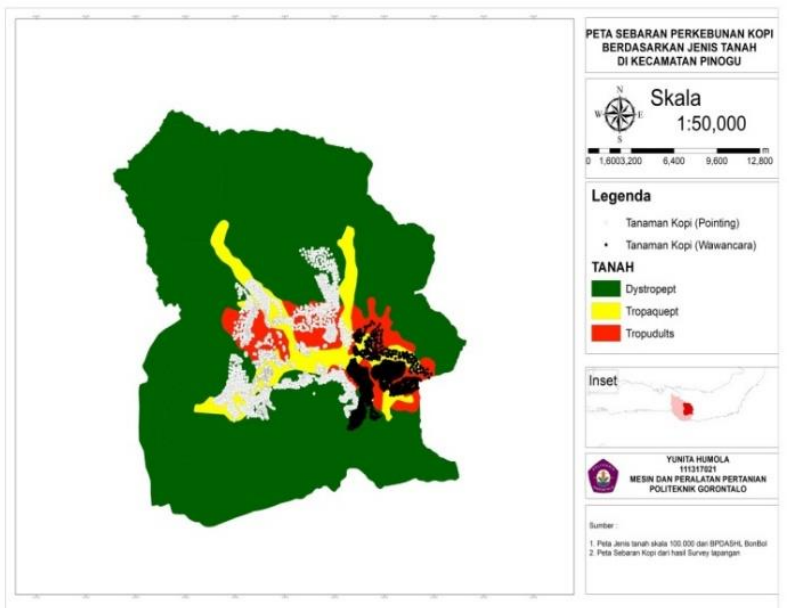

Gambar 4. Peta Sebaran Perkebunan Kopi di Kec. Pinogu Berdasarkan Jenis Tanah

\section{Sebaran Perkebunan Kopi Berdasarkan Status Kawasan}

Kondisi Geografis Kecamatan Pinogu yang berada di tengah-tengah area Taman Nasional Bogani-Nani Wartabone (TN-BNW) yang merupakan hutan lindung membuat banyaknya tanaman kopi yang berada di area kawasan (Gambar $5)$.

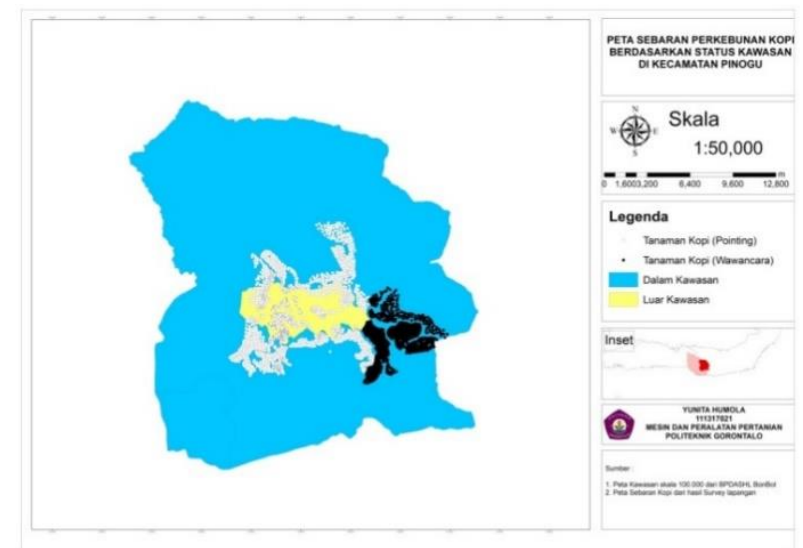

Gambar 5. Peta Sebaran Perkebunan Kopi Kec. Pinogu Berdasarkan Status Kawasan

Berdasarkan Gambar 5 diketahui bahwa banyak perkebunan kopi yang masuk dalam area berstatus kawasan. Hal ini seharusnnya ditindaklanjuti oleh pemerintah setempat untuk mengembalikan fungsi kawasan tersebut. Dimana Taman Nasional sebagai hutan lindung dalam Undang-undang No.41 tahun 1999 pasal 1 ayat 8 mendefinisikan sebagai kawasan hutan yang mempunyai fungsi pokok sebagai perlindungan system penyangga kehidupan yaitu untuk: mengatur tata air, mencegah banjir, mengendalikan erosi, mencegah intrusi air laut, dan memelihara kesuburan tanah.

Status kawasan Kec. Pinogu memiliki beberapa fungsi berdasarkan surat keputusan bernomor SK.6030/MENLHK-PKTL/KUH/PLA.2/11/2017 (Tabel 3).

Tabel 3. Luasan Fungsi Status Kawasan

\begin{tabular}{|l|l|l|c|c|}
\hline \multirow{2}{*}{ No } & Status & Fungsi Status & \multicolumn{2}{|c|}{ Luas } \\
\cline { 4 - 5 } & Kawasan & Kawasan & $(\mathrm{Ha})$ & $(\%)$ \\
\hline 1 & $\begin{array}{l}\text { Dalam } \\
\text { Kawasan }\end{array}$ & $\begin{array}{l}\text { Taman } \\
\text { Nasional } \\
\text { Bogani-Nani } \\
\text { Wartabone }\end{array}$ & 34.852 & 86,42 \\
\hline 2 & $\begin{array}{l}\text { Dalam } \\
\text { Kawasan }\end{array}$ & $\begin{array}{l}\text { Hutan } \\
\text { Produksi } \\
\text { Terbatas }\end{array}$ & 2.811 & 6,97 \\
\hline 3 & $\begin{array}{l}\text { Luar } \\
\text { Kawasan }\end{array}$ & $\begin{array}{l}\text { Areal Produksi } \\
\text { Terbatas }\end{array}$ & 2.933 & 7,27 \\
\hline \multicolumn{2}{|l|}{ Total } & $\mathbf{4 0 . 3 2 6}$ & $\mathbf{1 0 0}$ \\
\hline
\end{tabular}

Hampir sebagian besar wilayah Kecamatan Pinogu berada dalam status kawasan, dengan fungsi status Taman Nasional sebesar 86,42\% dan Hutan produksi Terbatas 6,97\%. Sedangkan, $7,27 \%$ wilayah Kecamatan Pinogu berada diluar kawasan.

\section{KESIMPULAN}

Berdasarkan uraian di atas dapat disimpulkan sebagai berikut:

1. Kecamatan Pinogu merupakan produsen kopi terbesar di Kabupaten Bone Bolango.

2. Desa Dataran Hijau merupakan desa yang memiliki perkebunan kopi terbesar, disusul oleh Desa Bangio, Desa Pinogu Permai, Desa Pinogu dan Desa Tilongibila dengan sebaran tersedikit.

3. Masih adanya perkebunan kopi yang berada di kelas curam antara $25-40 \%$ dan bahkan ada yang dikelas sangat curam $<40 \%$. Hal ini dapat menyebabkan erosi.

4. Wilayah Kecamatan Pinogu didominasi dengan tanah Dystropept sebesar $82 \%$, kemudian tanah tropaquept $9,4 \%$ dan tropudults $8,6 \%$. Namun, wilayah yang padat ditanami adalah wilayah berjenis tanah tropodults.

5. Kondisi Geografis Kecamatan Pinogu yang berada ditengah-tengah area Taman Nasional Bogani-Nani Wartabone (TN-BNW) yang 
merupakan hutan lindung membuat banyaknya tanaman kopi yang berada di area kawasan.

\section{DAFTAR PUSTAKA}

Adininggar, F.W., Suprayogi, A., \& Wijaya, A.P., 2016, Pembuatan Peta Potensi Lahan Berdasarkan Kondisi Fisik Lahan Menggunakan Metode Weighted Overlay, Jurnal Geodesi Undip, Vol. 5, No. 2, hal. 136146.

Anonim, 2017, Kopi Pinogu, dari Belantara Hutan Menuju Istana Presiden, https://regional.kompas.com/read/2017/09/27 /20160461/kopi-pinogu-dari-belantara-hutanmenuju-istana-presiden?page $=$ all

BPS, 2016, Kecamatan Pinogu dalam Angka 2016, Gorontalo: BPS Kabupaten Bone Bolango.

Hamidi, 2011, Aplikasi Sistem Informasi Geografis Berbasis Web Penyebaran Dana Bantuan Operasional Sekolah, Jurnal Masyarakat Informatika, Vol. 2, No. 3, hal. 1-14.

Suryani, S., Sasongko, P.S., \& Suharto, E., 2011, Sistem Informasi Geografis Pemetaan Sekolah Tingkat Pendidikan Dasar dan Menengah, Jurnal Masyarakat Informatika, Vol. 2, No. 3, hal. 39-50.

Susanto, A., Kharis, A., \& Khotimah, T., 2016, Sistem Informasi Geografis Pemetaan Lahan Pertanian Komoditi Hasil Panen Kabupaten Kudus, Jurnal Informatika, Vol. 10, No. 2, hal. 1233-1243.

Lampiran Surat Keputusan Menteri Lingkungan Hidup dan Kehutanan RI Nomor SK.6030/MENLHK-

PKTL/KUH/PLA.2/11/2017 tentang

Perkembangan Pengukuhan Kawasan Hutan. 